\title{
A New Approach to CFD Research: Combining AVL's Fire Code with User Combustion Model
}

\author{
Mario Baburić, Željko Bogdan and Neven Duić \\ Faculty of Mechanical Engineering and Naval Architecture \\ University of Zagreb \\ Department of Power Engineering \\ I. Lucica 5, 10000 Zagreb, Croatia \\ Mario.Baburic@fsb.hr,Zeljko.Bogdan@fssb.hr, Neven.Duic@fsb.hr
}

\begin{abstract}
A$ new oil-combustion model was implemented into the AVL's CFD code FIRE and validation performed. The validation consisted of the simulation and the comparison with the existing Magnussen model. For the simulation purpose the domain was determined first, while user-defined functions simulating conditions at the inlet were done subsequently. The comparisons with the Magnussen results as with some approximate experimental results were done at the end. The paper shows flexibility of AVL's code in usage of user-defined functions, which enables combining the advantages of a commercial code and user modelling.
\end{abstract}

Keywords: Reaction rate, swirl, oil-combustion, AVL FIRE, Computational Fluid Dynamics

\section{Introduction}

The Computational Fluid Dynamics (CFD) has developed into a power tool widely used in science, technology and industrial design applications, whenever fluid flow, heat transfer, combustion or many other complicated processes are significantly influencing the product. During decades of development of CFD codes, scientists were writing their own codes, that had to include not only the model of processes that were of interest, but also a whole spectrum of necessary CFD procedures, numerical techniques, preprocessing and post-processing. That has arrested much of the scientist effort in work that has been copied many times over, and was not actually producing added value.

The arrival of commercial CFD codes brought relief to many engineers that could now concentrate on the model and design, entrusting the application to do the rest of the work. But, those commercial codes, coming with a limited spectrum of standard models, although very valuable to the engineers, were not very useful to the researchers that were testing new models, or new procedures.

Only those commercial codes that allowed inclusion of user-defined models were of use to those researchers, like our group, that has a particular interest in combustion and heat transfer processes in industrial furnaces. In order to test a particular oil-combustion model, we had build our own code, ZONAL, ten years ago [2, 3, $4,9]$.

Implementing our oil-combustion model, which we called Bogdan Combustion Model (BCM), into the AVL's FIRE commercial code we have easily combined the best of both worlds, the professionally made pre- and post-processor and solver, and the freedom of the own coding [13].

After the installation of AVL's FIRE at the Power Engineering Department it was used for modelling the processes in the experimental furnace in IJmuiden, the Netherlands, for which the experimental data was available. The furnace is horizontal with nearly square cross-section.

Two different combustion models were used - Magnussen Combustion Model (MCM), which is part of the FIRE software, and the combustion model briefly described in [2] (hereafter referred to as BCM - Bogdan Combustion Model) which was additionally implemented into the code.

In order to increase the speed of computation only a quarter of the domain was considered with symmetry (cyclic) boundary conditions. Some approximation was introduced with this decision, because the arch roof was taken as a flat one, but this is considered as having negligible impact on the accuracy of the solution. The calculation procedure was time stepping. 


\section{Mathematical model}

The BCM was developed for the purpose of modelling combustion in oil-fired utility furnaces, in case when one is not particularly interested in the details of combustion, but when the flame dynamics is of crucial importance to the heat transfer in the furnace. It is using empirical knowledge [9] in order to include the influences of evaporation, induction, kinetics and coke combustion in an Arrhenius type expression.

The model is well suited for the whole range of typical oil flames, starting from partially premixed [1], to flames governed by several different streams of fuel and air. In order for the model to give physically sound results, the fuel must be considered premixed with the primary stream of air, since the BCM already takes implicitly into account the mixing time.

The model gives relatively low possibility to fine-tune various factors, but it is robust if used well, and works well for a wide range of typical industrial oil flames, as tested in previous work $[3,6,9]$.

The model is implemented through the reaction rate, which can be written as follows:

$\overline{r_{B}}=-\rho \cdot \frac{\partial \overline{Y_{B}}}{\partial t}=-\rho \cdot k \cdot \bar{Y}_{B}^{v_{B}} \cdot \bar{Y}_{O_{2}}^{v_{O_{2}}}$

Therefore, the reaction rate is always depending on fuel mass fraction, but it is only sensitive to oxygen mass fraction when it is low, delimited in the model by $3 \%$ :

$v_{B}=1$

$v_{O_{2}}=1 \quad$ for $\quad Y_{O_{2}}<0.03$

$v_{\mathrm{O}_{2}}=0 \quad$ for $\quad Y_{\mathrm{O}_{2}}>0.03$

Constant $k$, which could be characterised as a combustion velocity, will be written in the following manner:

$k=\frac{b_{k}}{\tau_{k}}$

The total time of combustion $\tau_{k}$, consists of three different parts:

-time of evaporation and induction $\tau_{e i}, \mathrm{~s}$

-time of oxidation $\tau_{o x}, \mathrm{~s}$

-time of coke combustion $\tau_{c c}$, $\mathrm{s}$

For each time mentioned, there is an expression gained by the experiment. For the time of evaporation and induction it is:

$\tau_{e i}=9.434 \cdot 10^{-7} \cdot e^{\frac{10^{5}}{R T}}+0.45695 \cdot d_{\mathrm{o}}^{2}$
Time of oxidation:

$\tau_{o x}=\frac{d_{\mathrm{o}}^{2}}{0.0032 \cdot(T-273.15)-1.79}$

Time of coke combustion:

$\tau_{c c}=\chi \cdot\left(\tau_{e i}+\tau_{o x}\right)$

$\chi \approx 0.75$ - constant for small droplet diameters

Combustion velocity coefficient $b_{k}$, used here for the purpose of switching on the influence of oxygen diffusion, has following values:

$b_{k}=100 / 3$ for $Y_{O_{2}}<0.03$

$b_{k}=1 \quad$ for $\quad Y_{O_{2}}>0.03$

This model gives a good coverage of a kinetic combustion, i.e., of the combustion when there is always sufficient oxygen for the combustion of evaporated fuel in the zone surrounding the droplet. But, in case of lack of oxygen, the whole combustion will be governed by the process of the oxygen diffusion in the zone of droplet. In this model this is solved by adjusting the values of $b_{k}$ and $v_{O_{2}}$ to different values when oxygen concentrations are small, making the reaction rate dependent on the availability of oxygen. This modification was made to the original model [2], in order to cover the flames with secondary air, like those of IJmuiden experimental furnace [3].

Fig. 1 shows the burner configuration. Fuel leaving the fuel nozzle is considered to be oil with the following composition:
carbon
$0.869[\mathrm{~kg} / \mathrm{kg}]$
hydrogen
$0.118[\mathrm{~kg} / \mathrm{kg}]$
sulphur
$0.013[\mathrm{~kg} / \mathrm{kg}]$

Fuel $\left(155 \mathrm{~kg} / \mathrm{h}, 116{ }^{\circ} \mathrm{C}\right)$ enters the furnace in a cone-shaped motion. Primary air $(455 \mathrm{~kg} / \mathrm{h}, 26$ ${ }^{\circ} \mathrm{C}$ ) enters the furnace in the swirled motion with the swirl number of 0.84 , while secondary air $\left(1849 \mathrm{~kg} / \mathrm{h}, 47^{\circ} \mathrm{C}\right)$ enters the furnace axially, normal to the front side.

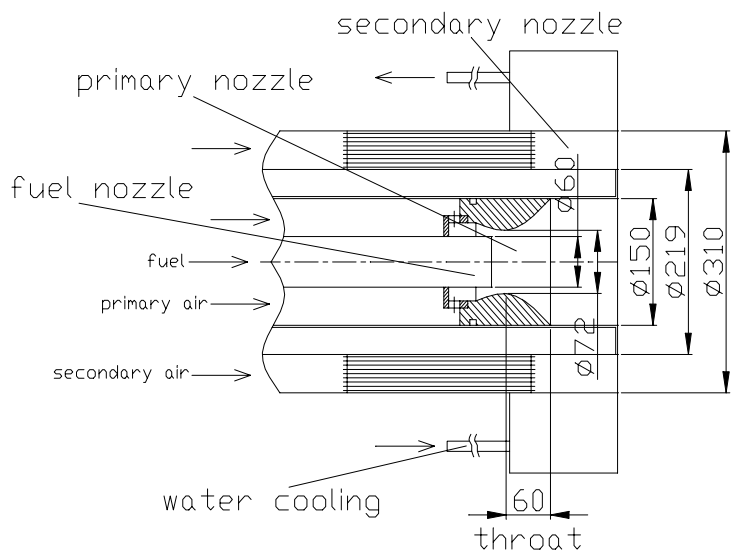

Figure 1 - Burner configuration 
The swirl number definition is needed for the modelling of the swirled motion of primary air at the inlet. The definition used in this work is one taken from [10], and it is a modified version. It looks like the following:

$$
S=\frac{G_{\Phi}}{R \cdot G_{x}^{\prime}}=\frac{2 \cdot \pi \cdot \int_{R_{1}}^{R_{2}} \rho \cdot U \cdot W(r) \cdot r^{2} d r}{R \cdot 2 \cdot \pi \cdot \int_{R_{1}}^{R_{2}} \rho \cdot U^{2} \cdot r d r}(6)
$$

Assuming that $\rho=$ const. and $U=$ const. and putting $W(r)=r \cdot \omega$ into (6) one obtains:

$$
S=\frac{\omega}{R \cdot U} \cdot \frac{\int_{R_{1}}^{R_{2}} r^{3} d r}{\int_{R_{1}}^{R_{2}} r d r}
$$

Assuming that $R=\left(R_{1}+R_{2}\right) / 2$ one gets the final expression for the swirl number:

$$
S=\frac{R_{1}^{2}+R_{2}^{2}}{R_{1}+R_{2}} \cdot \frac{\omega}{U}
$$

\section{Results}

As mentioned before, the domain was divided in a quarter and the cyclic boundaries were used instead of using the whole domain. This was possible when approximating the roof of the furnace as a flat one, so the cyclic symmetry could be applied. This increased the calculation speed substantially. Fig. 2 shows the domain used in calculations.

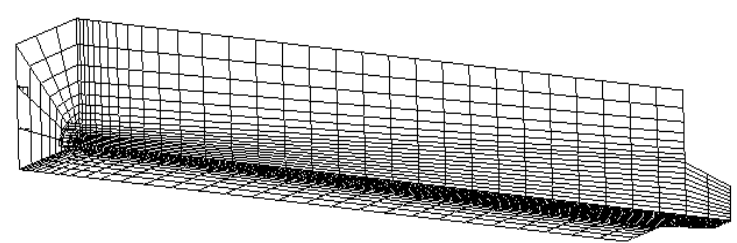

Figure 2 - Domain

The extension at the far end of the furnace is modelled in order to avoid possible recirculating flow at the outlet boundary, which is undesirable from the computational aspect, according to [11]. This modelling strategy is often called computational chimney.

Table 1 contains test cases that were calculated. When referring to them later, one does it by specifying the number of the particular test case - e.g., test case 1 .
Table 1 - Test cases

\begin{tabular}{|c||c|c|c|}
\hline $\begin{array}{c}\text { Case } \\
\text { No. }\end{array}$ & $\begin{array}{c}\text { Comb. } \\
\text { Model }\end{array}$ & $\begin{array}{c}\text { Fuel/primary } \\
\text { air inlet } \\
\text { mixture }\end{array}$ & $\begin{array}{c}\text { Side walls } \\
\text { boundary }\end{array}$ \\
\hline \hline 1 & Bogdan & Premixed & $\begin{array}{c}\text { Zero heat } \\
\text { flux }\end{array}$ \\
\hline 2 & $\begin{array}{c}\text { Magnus } \\
\text { sen }\end{array}$ & Premixed & $\begin{array}{c}\text { Zero heat } \\
\text { flux }\end{array}$ \\
\hline
\end{tabular}

User defined function was used for the implementation of the model into the main program. When compiled and linked properly it was used by the main program in each iteration loop, thus determining the reaction rate, according to $\mathrm{BCM}$, in right fashion. Another user defined function was used when simulating the conditions at the inlet. Namely, swirl number, as described before, had to be modelled separately. This way the swirled motion of the primary air at the inlet was gained. In the main program, thus, the flow and the energy equations had to be solved. Additionally, one had to enable the species transport and the combustion modules. Other modules, like spray, two phase flows, etc., were not of interest in our problem and they were turned off. The flow was considered as the compressible one and the k- $\varepsilon$ model was used when accounting for turbulence. In all equations hybrid differencing scheme with blending factors was used. Dynamic adjustment of underrelaxation factors (available in Fire) during calculation allowed good and rapid convergence. Initialization mode plays sometimes an important role in CFD calculations, when considering the convergence of the solution, but in our case uniform initialization of the domain with air at standard conditions (293.15 K and $101325 \mathrm{~Pa})$ as the medium, caused no convergence problems. Calculation procedure itself was time stepping. For both test cases first the fuel and the air were left to enter the domain in cold flow (i.e. with no combustion), and then, at $3.05 \mathrm{~s}$, the ignition occurred and combustion started.

Fig. 3 shows the temperature field for the test case $1(\mathrm{BCM})$ in the real time $7.5 \mathrm{~s}$, while Fig. 4 shows the same for the test case 2 (MCM). One should consider those results as transient, in a particular time of $7.5 \mathrm{~s}$, and not as final ones which would be gained if using steady state calculation procedure instead of time stepping, as in our case. 


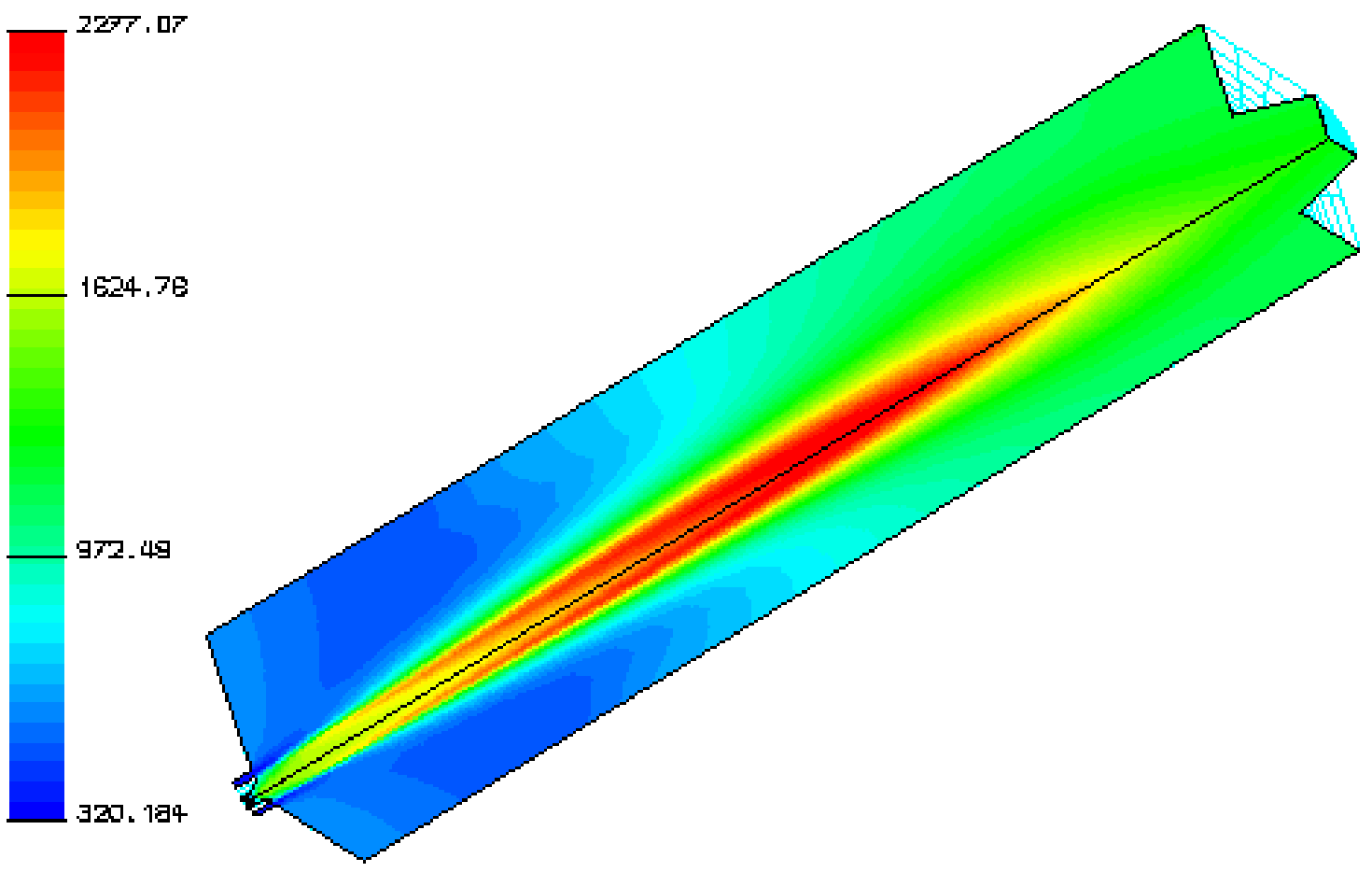

Figure 3 - Temperature field (at $7.82 \mathrm{~s}$ ); test case 1

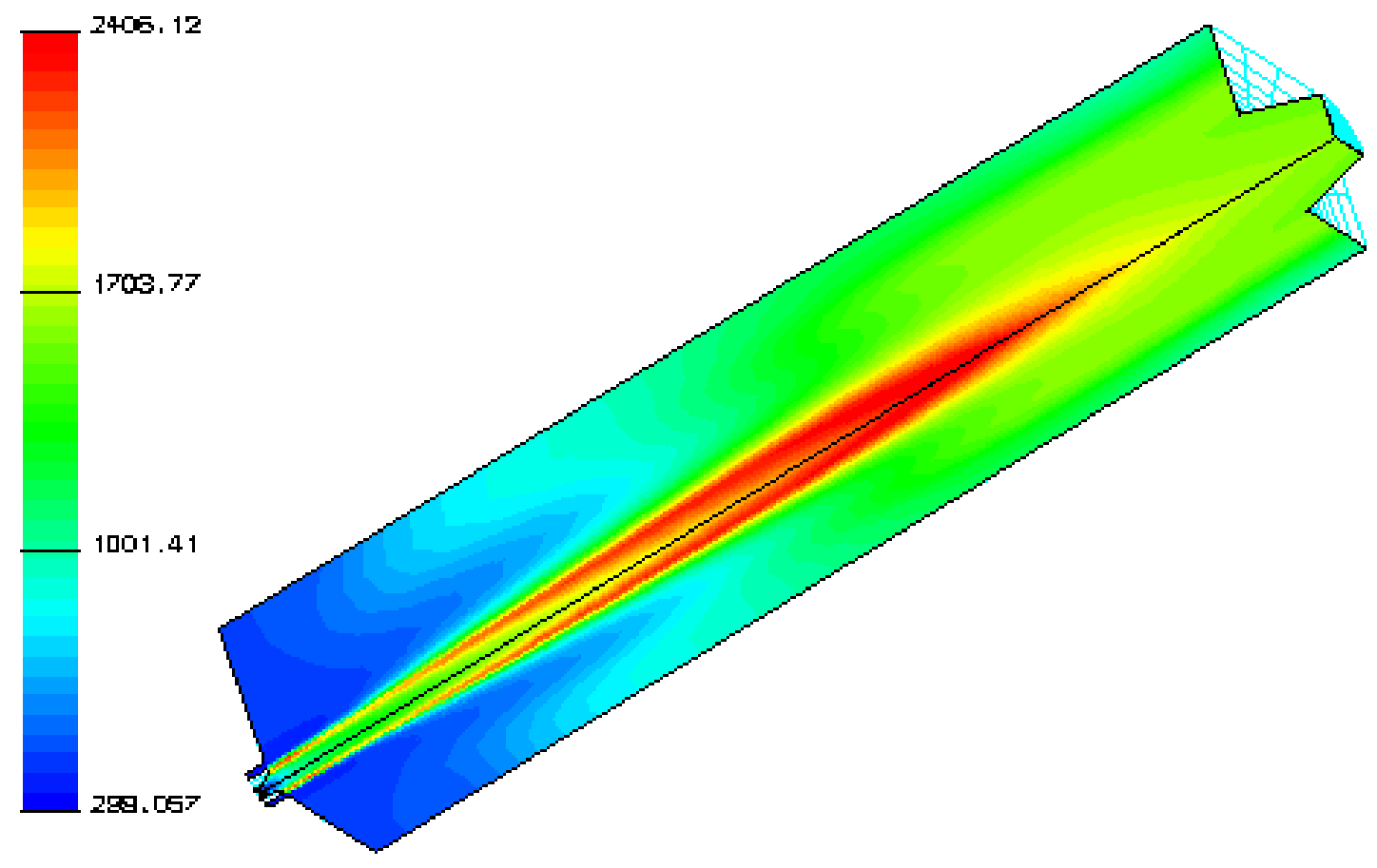

Figure 4 - Temperature field (at $7.82 \mathrm{~s}$ ); test case 2

Figs. 5 and 6 that follow show comparison between temperatures along the furnace at two different points normal to axis in central horizontal plane. Fig. 7 and Fig. 8, on the other hand, show comparison between oxygen concentrations along the furnace at the same points. The experimental data for oxygen concentrations along the furnace was available for a very similar case and it is given in Fig. 7 and Fig. 8 additionally. 


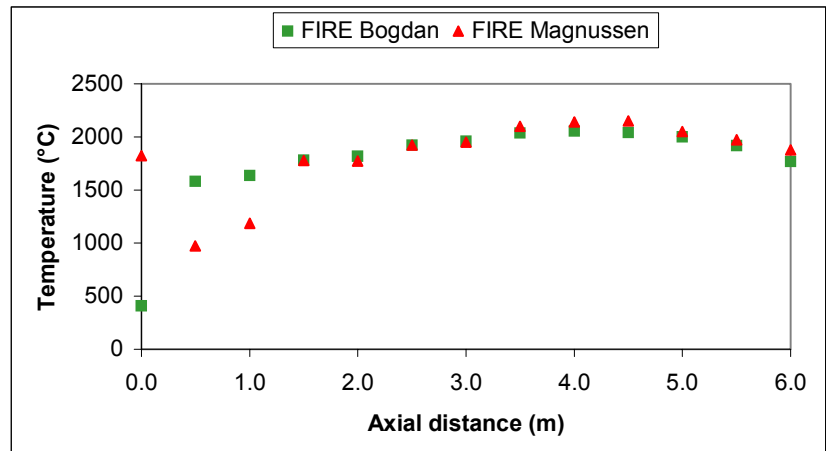

Figure 5 - The temperature comparison for BCM and MCM data at the points placed $0.1 \mathrm{~m}$ normal to axis in central horizontal plane

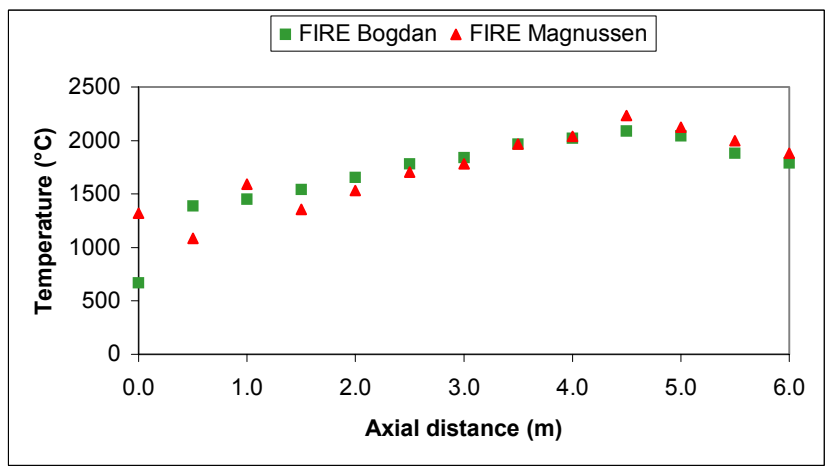

Figure 6 - The temperature comparison for BCM and MCM data at the points placed $0.05 \mathrm{~m}$ normal to axis in central horizontal plane

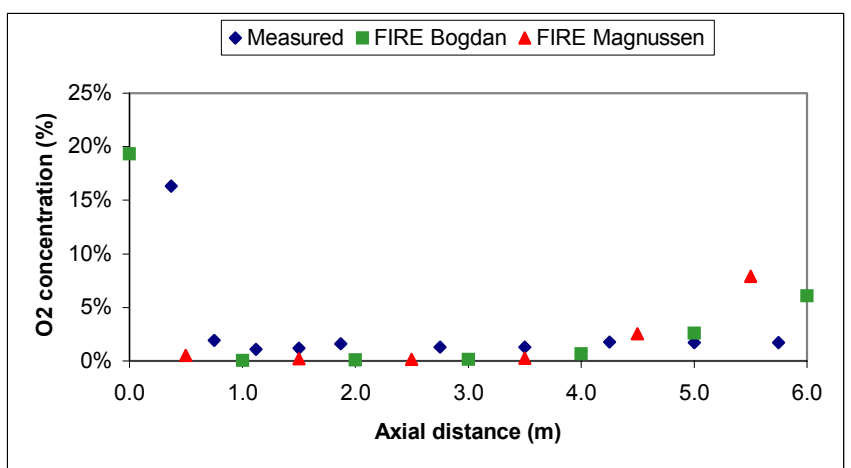

Figure 7 - The $\mathrm{O}_{2}$ concentration comparison for measured, BCM and MCM data at the points placed $0.1 \mathrm{~m}$ normal to axis in central horizontal plane

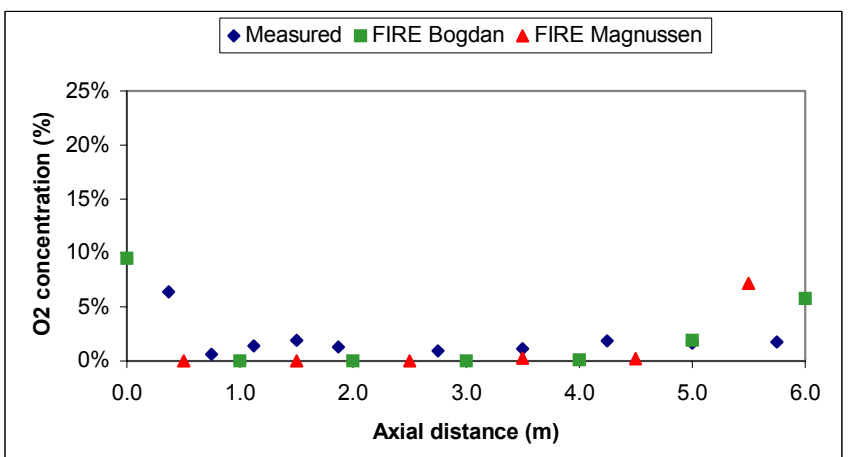

Figure $8-$ The $\mathrm{O}_{2}$ concentration comparison for measured, BCM and MCM data at the points placed $0.05 \mathrm{~m}$ normal to axis in central horizontal plane 


\section{Conclusion}

The temperature fields are shown and can easily be compared on Figs. 3 and 4. As one can see, there is only a slightly difference between those two temperature patterns. The maximum temperatures are slightly different, as some temperatures near the end of the furnace, but in general one can easily conclude that a very good degree of accordance is achieved. The temperature at the outlet turned out to be pretty high, which might look impossible at the first sight, but there is a physical explanation for that. Namely, in the absence of the heat removal through the walls, as set in our cases, and considering the fact that the energy equation at the outlet should be satisfied, entire heat that enters the furnace must equal to the heat which leaves the furnace. In our cases the heat leaving the furnace is only the heat of the flue gases at the outlet, which depends only on the mass-flow and the temperature of those gases. So, the temperature at the outlet should be sufficiently high in order to satisfy the rule of the energy balance, as it is in our cases. Further more, the conservation of properties was held when BCM or MCM was applied, a simple, but important test of the correct implementation. The global mass conservation was checked, and mass fractions have, by the time of reaching outlet, stabilised on stoichiometric values.

The both models are predicting oxygen mass fractions rather well, although under-predicting it consistently in the flame zone (Figs. 7 and 8).

This paper has shown an example how it is possible to develop and test own model by implementing it into a commercial code. The model developing cycle time shortens significantly, since the tedious work on developing own pre-processor, solver and a whole spectrum of standard model and methods that are needed, can be avoided. The AVL's FIRE code has shown great flexibility in userdefined model implementation.

\section{References}

[1] Bielert U, Sichel M. Numerical Simulation Of Premixed Combustion Processes In Closed Tubes. Combustion \& Flame. 114(34):397-419; 1998 Aug-Sep.

[2] Bogdan Ž, Duić N. Three-dimensional simulation of the combustion process in an oil-fired furnace. ITI. Pula; 1993
[3] Bogdan Ž, and Duić N. The mathematical model of the steam generator combustion chamber. Proc $24^{\text {th }}$ Symposium KoREMA, Zagreb. pg. 77; 1992.

[4] Bogdan Ž, Duić N, and Schneider DR. Three-dimensional simulation of the performance of an oil-fired combustion chamber. Proc. of the $2^{\text {nd }}$ European Thermal Sciences \& $14^{\text {th }}$ UIT National Heat Transfer Conference, Rome.1493-1495; 1996.

[5] Coelho PJ, Carvalho MG. Evaluation Of A Three-Dimensional Mathematical Model Of A Power Station Boiler. Journal of Engineering for Gas Turbines \& PowerTransactions of the ASME. 118(4):887-895; 1996 Oct.

[6] Duić N. Trodimenzionalni matematički model procesa u ložištu generatora pare. magisterij, FSB, Zagreb. 121 str.; 1993.

[7] Görner K Technische Verbrennungssysteme, Springer-Verlag, Berlin;1991

[8] Johnson TR, Application of the Zone Method of Analysis to the Calculation of Heat Transfer from Luminous Flames. PhD thesis, University of Sheffield; 1971.

[9] Kylagin LV, and Ohotnikov SS. Sžiganje tjaželjnih žitkih topliv: in Russian. Nedra, Moscow; 1967.

[10] Mahmud T. Aerodynamic and combustion characteristics of swirl burners for pulverized coal. $\mathrm{PhD}$ thesis, the University of Newcastle; 1986.

[11] Patankar SV, Numerical Heat Transfer and Fluid Flow. Hemisphere Publishing Corporation, Washington; 1980.

[12] Shih TM. Numerical Heat Transfer. Hemisphere Publishing Corporation, Washington; 1984

[13] Stern F, Wilson RV, Coleman HW, Paterson EG. Comprehensive approach to verification and validation of CFD simulations - Part 1: Methodology and procedures. Journal of Fluids EngineeringTransactions of the ASME. 123(4):793-802; 2001 Dec. 